\title{
Studi Hubungan Antara Faktor Lingkungan Fisik Rumah Dengan Penderita TB Paru BTA di Aceh Selatan
}

\author{
${\text { Mawardi }{ }^{1, *}, \text { Rychad Sambera }}^{2}$, Irma Hamisah ${ }^{3}$ \\ ${ }^{1}$ Balai Pelatihan Kesehatan Aceh - Banda Aceh \\ ${ }^{2,3}$ Fakultas Kesehatan Masyarakat Universitas Muhammadiyah Aceh - Banda Aceh \\ *Koresponden email: mawardi.ibrahim@gmail.com
}

Diterima: 30 Desember 2018

Disetujui: 8 Februari 2019

\begin{abstract}
Pulmonary TB is a world problem especially in developing countries including Indonesia. In Indonesia, it is estimated that every year 450,000 new cases of pulmonary TB appear with death estimated at 175,000 per year. This study aims to determine the relationship between physical environmental factors of houses with pulmonary TB patients with AFB (+) at Lhok Bengkuang Health Center, Tapaktuan Subdistrict, South Aceh Regency in 2018. The population in this study were pulmonary TB patients smear (+) recorded in the case data report in the working area of Lhok Bengkuang Health Center, Tapaktuan Subdistrict, South Aceh Regency in 2017, which is 36 patients with pulmonary TB (+) and 36 non-pulmonary TB sufferers. The results of the univariate study showed $52.8 \%$ of respondents with occupant density did not meet the requirements, $55.6 \%$ of respondents with house floors did not meet the requirements, $51.4 \%$ of respondents with lighting did not meet the requirements, $51.4 \%$ of respondents with house ventilation did not meet the requirements . The results of bivariate analysis showed that there was a relationship between occupant density $(\mathrm{P}$ value $=0.001)$, house floor $(\mathrm{P}$ value $=0.015)$, lighting $(\mathrm{P}$ value $=0.034)$, ventilation $(\mathrm{P}$ value $=0.038)$ with pulmonary $\mathrm{TB}$ patients with AFB (+) in the area of Lhok Bengkuang District Health Center, Tapaktuan Subdistrict, South Aceh Regency.
\end{abstract}

Keywords : occupant density, house floor, lighting, home ventilation, pulmonary TB smear (+)

\begin{abstract}
Abstrak
Penyakit TB paru merupakan masalah dunia terutama di negara-negara sedang berkembang termasuk Indonesia. Di Indonesia di perkirakan tiap tahun muncul 450.000 kasus TB paru baru dengan kematian di perkirakan 175.000 pertahun. Penelitian ini bertujuan untuk mengetahui hubungan antara faktor lingkungan fisik rumah dengan penderita TB paru BTA (+) di Puskesmas Lhok Bengkuang Kecamatan Tapaktuan Kabupaten Aceh Selatan Tahun 2018. Populasi dalam penelitian ini adalah penderita TB paru BTA $(+)$ yang tercatat dalam laporan data kasus di wilayah kerja Puskesmas Lhok Bengkuang Kecamatan Tapaktuan Kabupaten Aceh Selatan Tahun 2017 yaitu sebanyak 36 penderita TB Paru (+) dan 36 penderita non TB Paru. Hasil penelitian univariat menunjukkan 52,8\% responden dengan kepadatan penghuni tidak memenuhi syarat, 55,6\% responden dengan lantai rumah tidak memenuhi syarat, $51,4 \%$ responden dengan pencahayaan tidak memenuhi syarat, $51,4 \%$ responden dengan ventilasi rumah tidak memenuhi syarat. Hasil analisis bivariat menunjukkan ada hubungan kepadatan penghuni $(\mathrm{P}$ value $=0,001)$, lantai rumah $(\mathrm{P}$ value $=0,015)$, pencahayaan $(\mathrm{P}$ value $=$ $0,034)$, ventilasi $(\mathrm{P}$ value $=0,038)$ dengan dengan penderita TB paru BTA $(+)$ di Wilayah Kerja Puskesmas Lhok Bengkuang Kecamatan Tapaktuan Kabupaten Aceh Selatan Tahun 2018.
\end{abstract}

Kata Kunci: kepadatan penghuni, lantai rumah, pencahayaan, ventilasi rumah, TB paru BTA(+)

\section{Pendahuluan}

Mewujudkan kesehatan yang optimal bagi masyarakat adalah merupakan salah satu tujuan untuk pembangunan dalam bidang kesehatan. Berdasarkan Undang-undang Kesehatan No. 36 Tahun 2009 pasal 47 menyatakan bahwa untuk mewujudkan derajat kesehatan yang setinggi-tingginya bagi masyarakat, diselenggarakan upaya kesehatan masyarakat. Upaya kesehatan diselenggarakan dalam bentuk kegiatan dengan pendekatan promotif, preventifdan rehabilitatif yang dilaksanakan secara terpadu, menyeluruh dan berkesinambungan (Depkes RI, 2012).

Ditinjau dari segi epidemiologi derajat kesehatan masyarakat dipengaruhi oleh 4 faktor yaitu faktor lingkungan, faktor perilaku, faktor pelayanan kesehatan dan faktor keturunan. Ditinjau dari epidemiologi ada kegiatan yang dilakukan untuk derajat kesehatan. Salah satunya pemberantasan 
Tabel 1. Populasi dan sampel penelitian

\begin{tabular}{clccc}
\hline No & \multicolumn{1}{c}{ Nama Desa } & Kasus & Kontrol & Jumlah \\
\hline 1 & Hilir & 7 & 7 & 14 \\
2 & Hulu & 3 & 3 & 6 \\
3 & Jambo Apha & 3 & 3 & 6 \\
4 & Lhok Benkuang & 5 & 5 & 10 \\
5 & Lhok Keutapang & 7 & 7 & 14 \\
6 & Padang & 6 & 6 & 12 \\
7 & Pasar & 5 & 5 & 10 \\
\hline \multicolumn{2}{r}{ Total } & 36 & 36 & 72
\end{tabular}

penyakit baik menular maupun tidak menular. Tujuan dari program pemberantasan penyakit adalah mencegah terjadinya penyakit, menurunkan angka kematian dan angka kesakitan serta mengurangi akibat buruk dari penyakit baik yang menular maupun tidak menular (Bustan, 2012).

Tuberculosis merupakan penyakit menular yang sebagian besar disebabkan oleh kuman Mycrobacterium Tuberculosis. Kuman yang berbentuk batang ini mempunyai sifat istimewa, yaitu dapat bertahan terhadap penghilangan warna dengan asam dan alkohol, sehingga disebut sebagai Basil Tahan Asam (BTA) (Murti, 2011).

Lingkungan merupakan hal yang tidak terpisahkan dari aktivitas kehidupan manusia, baik itu lingkungan secara fisik, biologis maupun sosial sehingga sangat berperan dalam proses terjadinya gangguan kesehatan masyarakat, termasuk gangguan kesehatan berupa penyakit tuberkulosis (Notoatmodjo, 2012).

Lingkungan rumah merupakan salah satu faktor yang memberikan pengaruh besar terhadap status kesehatan penghuninya. Lingkungan rumah juga merupakan salah satu faktor yang berperan dalam penyebaran kuman tuberkulosis. Kuman tuberkulosis dapat hidup selama 1-2 jam bahkan sampai beberapa hari hingga berminggu-minggu tergantung pada ada tidaknya sinar ultraviolet, ventilasi yang baik, kelembaban, suhu rumah dan kepadatan penghuni rumah (Atmosukarto, 2012).

Alasan utama meningkatnya beban TB paru global ini antara lain disebabkan kemiskinan pada berbagai penduduk yang membuat terlantar dan kurangnya biaya berobat, tidak hanya pada negara yang sedang berkembang tetapi juga pada penduduk perkotaan tertentu di negara maju, adanya perubahan demografik dengan meningkatnya penduduk dunia dan perubahan dari struktur usia manusia yang hidup, perlindungan kesehatan yang tidak mencukupi pada kelompok yang rentan terutama di negeri miskin, tidak memadainya pendidikan mengenai TB dikalangan masyarakat (Sudoyo dkk,2012).

Penyakit tuberkulosis paru merupakan penyakit yang disebabkan oleh Mycobacterium tuberculosis yang telah menginfeksi hampir sepertiga penduduk dunia dan pada sebagian besar negara di dunia tidak dapat mengendalikan penyakit TBC ini disebabkan banyaknya penderita yang tidak berhasil disembuhkan. WHO dalam Annual Report on Global TB Control 2003 menyatakan terdapat 22 negara dikategorikan sebagai high burden countris terhadap TBC, termasuk Indonesia (WHO, 2017).

Di Indonesia, prevalensi TB paru dikelompokkan dalam tiga wilayah, yaitu wilayah Sumatera (33\%), wilayah Jawa dan Bali (23\%), serta wilayah Indonesia Bagian Timur (44\%). Penyakit TB paru merupakan penyebab kematian nomor tiga setelah penyakit jantung dan saluran pernafasan pada semua kelompok usia serta nomor satu untuk golongan penyakit infeksi. Korban meninggal akibat TB paru di Indonesia diperkirakan sebanyak 61.000 kematian tiap tahunnya (Dinas Kesehatan Aceh, 2017).

Berdasarkan latar belakang diatas, sehingga peneliti ingin meneliti tentang hubungan antara faktor lingkungan fisik rumah dengan penderita TB paru BTA $(+)$ di Wilayah Kerja Puskesmas Lhok Bengkuang Kecamatan Tapaktuan Kabupaten Aceh Selatan Tahun 2018.

Penelitian ini bertujuan untuk mengetahui "hubungan antara faktor lingkungan fisik rumah dengan penderita TB paru BTA $(+)$ di Wilayah Kerja Puskesmas Lhok Bengkuang Kecamatan Tapaktuan Kabupaten Aceh Selatan Tahun 2018. Ruang lingkup penelitian ini adalah pencahayaan rumah, kepadatan penghuni, lantai rumah dan ventilasi rumah yang tidak memadai yang ingin peneliti teliti.

\section{Studi Kepustakaan \\ 2.1 Pengertian TB Paru}

Tuberkulosis paru adalah penyakit menular yang disebabkan oleh kuman Mycobacterium tuberculosis tipe Humanus. Kuman tuberkulosis pertama kali ditemukan oleh Robert Koch pada tahun 1882. Jenis kuman tersebut adalah Mycobacterium tuberculosis, Mycobacterium africanum dan Mycobacterium bovis. Basil tuberkulosis termasuk dalam genus Mycobacterium, suatu anggota dari 
Tabel 2. Distribusi frekuensi kepadatan penghuni di wilayah kerja Puskesmas Lhok Bengkuang Kabupaten Aceh Selatan tahun 2018

\begin{tabular}{cccccc}
\hline \multirow{2}{*}{ No. } & \multirow{2}{*}{ Kepadatan Penghuni } & \multicolumn{3}{c}{ Kasus } & \multicolumn{2}{c}{ Kontrol } \\
\cline { 3 - 6 } & & f & \% & f & \% \\
\hline 1 & Tidak memenuhi Syarat & 26 & 72,2 & 12 & 33,3 \\
2 & Memenuhi Syarat & 10 & 27,8 & 24 & 66,7 \\
\hline Jumlah & 36 & 100 & 36 & 100 \\
\hline
\end{tabular}

Sumber : Data primer (Diolah, 2018)

family dan termasuk ke dalam ordo Actinomycetales. Mycobacterium tuberculosis menyebabkan sejumlah penyakit berat pada manusia dan juga penyebab terjadinya infeksi tersering (Aditama,2012).

Basil-basil tuberkel di dalam jaringan tampak sebagai mikroorganisme berbentuk batang, dengan panjang bervariasi antara $1-4$ mikron dan diameter 0,3 - 0,6 mikron. Bentuknya sering agak melengkung dan kelihatan seperti manik - manik atau bersegmen. Basil tuberkulosis dapat bertahan hidup selama beberapa minggu dalam sputum kering, ekskreta lain dan mempunyai resistensi tinggi terhadap antiseptik, tetapi dengan cepat menjadi inaktif oleh cahaya matahari, sinar ultraviolet atau suhu lebih tinggi dari $60^{\circ} \mathrm{C}$ (Atmosukarto, 2012).

Mycobacterium tuberculosis masuk ke dalam jaringan paru melalui saluran napas (droplet infection) sampai alveoli, terjadilah infeksi primer. Selanjutnya menyebar ke getah bening setempat dan terbentuklah primer kompleks. Infeksi primer dan primer kompleks dinamakan TB primer, yang dalam perjalanan lebih lanjut sebagian besar akan mengalami penyembuhan (Bustan, 2012).

\subsection{Cara Penularan}

Sumber penularan adalah penderita TB Paru BTA positif. Pada waktu batuk atau bersin, penderita menyebarkan kuman ke udara dalam bentuk droplet (percikan dahak). Droplet yang mengandung kuman dapat bertahan di udara pada suhu kamar selama beberapa jam (Crofton, 2012). Orang dapat terinfeksi kalau droplet tersebut terhirup kedalam saluran pernafasan, kuman TB Paru tersebut dapat menyebar dari paru ke bagian tubuh lainnya, melalui sistem peredaran darah, sistem saluran limfe, saluran nafas, atau penyebaran langsung ke bagian-bagian tubuh lainnya (Daryatno, 2010). Daya penularan dari seorang penderita ditentukan oleh banyaknya kuman yang dikeluarkan dari parunya. Makin tinggi derajat positif hasil pemeriksaan dahak negatip (tidak terlihat kuman), maka penderita tersebut dianggap tidak menular (Soemirat, 2012).

Kemungkinan seseorang terinfeksi TB Paru ditentukan oleh konsentrasi droplet dalam udara dan lamanya menghirup udara tersebut. Faktor yang mempengaruhi kemungkinan seseorang menjadi penderita Tuberkulosis paru adalah daya tahan tubuh yang rendah, diantarannya gizi buruk atau HIV/AIDS (Soemirat, 2012).

Diagnosis TB paru pada orang dewasa dapat ditegakkan dengan ditemukannya BTA pada pemeriksaan dahak secara mikroskopis. Hasil pemeriksaan dinyatakan positif apabila sedikitnya dua tiga spesimen SPS BTA hasilnya positif.Bilahanya 1 yang positif perlu diadakan pemeriksaan lebih lanjut yaitu foto rontgen dada atau pemeriksan dahak SPS diulang (Crofton, 2012).

\subsection{Penyebab \& Gejala Penyakit TB Paru}

Penyebab dari penyakit ini adalah bakteri Mycobacterium tuberculois. Ukuran dari bakteri ini cukup kecil yaitu 0,5-4 mikron x 0,3-0,6 mikron dan bentuk dari bakteri ini yaitu batang, tipis, lurus atau agak bengkok, bergranul, tidak mempunyai selubung tetapi kuman ini mempunyai lapisan luar yang tebal yang terdiri dari lipoid (terutama asam mikolat). Sifat dari bakteri ini agak istimewa, karena bakteri ini dapat bertahan terhadap pencucian warna dengan asam dan alkohol sehingga sering disebut dengan bakteri tahan asam (BTA). Selain itu bakteri ini juga tahan terhadap

Tabel 3. Distribusi frekuensi lantai rumah di wilayah kerja Puskesmas Lhok Bengkuang Kabupaten Aceh Selatan tahun 2018

\begin{tabular}{cccccc}
\hline \multirow{2}{*}{ No. } & \multirow{2}{*}{ Lantai Rumah } & \multicolumn{2}{c}{ Kasus } & \multicolumn{2}{c}{ Kontrol } \\
\cline { 3 - 6 } & Tidak memenuhi Syarat & $\mathbf{f}$ & $\mathbf{\%}$ & $\mathbf{f}$ & $\mathbf{\%}$ \\
\hline 1 & 23 & 63,9 & 17 & 47,2 \\
2 & Memenuhi Syarat & 13 & 36,1 & 19 & 52,8 \\
\hline Jumlah & 36 & 100 & 36 & 100 \\
\hline
\end{tabular}


Tabel 4. Distribusi frekuensi pencahayaan di wilayah kerja Puskesmas Lhok Bengkuang Kabupaten Aceh Selatan tahun 2018

\begin{tabular}{crcccc}
\hline \multirow{2}{*}{ No. } & \multirow{2}{*}{ Pencahayaan } & \multicolumn{2}{c}{ Kasus } & \multicolumn{2}{c}{ Kontrol } \\
\cline { 3 - 6 } & Tidak memenuhi Syarat & f & \% & f & \% \\
\hline 1 & 22 & 61,1 & 15 & 41,7 \\
2 & Memenuhi Syarat & 14 & 38,9 & 21 & 58,3 \\
\hline Jumlah & 36 & 100 & 36 & 100 \\
\hline
\end{tabular}

Sumber : Data primer (Diolah, 2018)

suasana kering dan dingin. Bakteri ini dapat bertahan pada kondisi rumah atau lingkungan yang lembab dan gelap bisa sampai berbulan-bulan namun bakteri ini tidak tahan atau dapat mati apabila terkena sinar, matahari atau aliran udara (Widoyono, 2011).

TB paru merupakan penyakit menular yang disebabkan oleh kuman Microbacterium tuberculosis, sebagian besar kuman terdiri atas asam lemak (lipid), lipid inilah yang membuat kuman lebih tahan terhadap asam dan gangguan kimia dan fisik (Hiswani, 2014).

Menurut Amir (2012) gejala-gejala umum TB paru adalah :

1. Berat badan turun tanpa sebab yang jelas atau pada anak berat badan tidak naik dalam 1 bulan dengan penanganan gizi.

2. Tidak nafsu makan dan pada anak terlihat gagal tumbuh serta penambahan berat badan tidak memadai sesuai umur.

3. Demam lama dan berulang tanpa sebab yang jelas (bukan tifoid, malaria atau infeksi saluran nafas akut), dapat disertai adanya keringat pada malam hari.

4. Adanya pembesaran kelenjar seperti di leher atau ketiak.

5. Batuk lama lebih 30 hari dengan atau tanpa dahak atau dapat juga berupa batuk darah.

Menurut Amir (2012) gejala sistemik TB paru

1. Gejala secara sistemik pada umumnya penderita akan mengalami demam. Demam berlangsung pada sore dan malam hari, disertai keringat dingin meskipun tanpa aktifitas, kemudian kadang hilang. Gejala ini akan timbul lagi beberapa bulan kemudian seperti demam, influenza biasa, dan kemudian seolah-olah sembuh tidak ada demam.
2. Gejala lain adalah Malaise (perasaan lesu) bersifat berkepanjangan kronis, disertai rasa tidak fit, tidak enak badan, lemah, lesu, pegalpegal, nafsu makan berkurang, badan semakin kurus, pusing, serta mudah lelah. Gejala sistemik ini terdapat baik pada TB Paru maupun TB yang menyerang organ lain.

\subsection{Pengobatan dan Pencegahan Penyakit TB Paru}

Menurut Zulfikar (2012) tujuan pengobatan TB paru untuk menyembuhkan penderita, mencegah kematian, menurunkan penularan ke orang lain dan mencegah resistensi terhadap obat anti tuberkulosis.

Pengobatan yang dianjurkan oleh WHO dan IULTLD dengan paduan Obat Anti Tuberkulosis (OAT) standar yang terdiri dari Isoniazid, Rifampisin, Pirazinamid, Streptomycin dan Ethambutol dengan standar yang dinyatakan dalam kategori 1, kategori 2, kategori 3 dan sisipan (Sugiarto, 2012). Berdasarkan paduan obat tersebut diatas maka program TB paru di Indonesia menggunakan paduan OAT yang disediakan dalam bentuk paket dengan tujuan memudahkan pemberian obat kepada penderita dan menjamin kelangsungan pengobatan sampai selesai, satu paket untuk setiap penderita dalam satu masa pengobatan.

Tindakan yang harus dilakukan agar tidak tertular penyakit TB adalah menjalankan pola hidup sehat, tapi tidak hanya cukup dengan menjalankan pola hidup sehat, hal lain yang harus dilakukan agar terhindar dari penyakit TB paru adalah memberikan imunisasi BCG pada anak balita, vaksin sebaiknya diberikan sejak anak masih kecil agar terhindar dari penyakit tersebut, bila ada yang dicurigai sebagai penderita TB paru maka harus diobati sampai tuntas agar tidak tambah parah dan terjadi penularan,

Tabel 5. Distribusi frekuensi ventilasi rumah di wilayah kerja Puskesmas Lhok Bengkuang Kabupaten Aceh Selatan tahun 2018

\begin{tabular}{crcccc}
\hline \multirow{2}{*}{ No. } & \multirow{2}{*}{ Ventilasi Rumah } & \multicolumn{2}{c}{ Kasus } & \multicolumn{2}{c}{ Kontrol } \\
\cline { 3 - 6 } & & $\mathbf{f}$ & $\mathbf{\%}$ & $\mathbf{f}$ & $\mathbf{\%}$ \\
\hline 1 & Tidak memenuhi Syarat & 20 & 55,6 & 17 & 47,2 \\
2 & Memenuhi Syarat & 16 & 44,4 & 19 & 52,8 \\
\hline Jumlah & 36 & 100 & 36 & 100 \\
\hline
\end{tabular}

Sumber : Data primer (Diolah Tahun 2018) 
Tabel 6. Hubungan kepadatan penghuni dengan penderita TB paru BTA (+) di wilayah kerja Puskesmas Lhok Bengkuang Kabupaten Aceh Selatan tahun 2018

\begin{tabular}{|c|c|c|c|c|c|c|c|c|c|c|}
\hline \multirow{3}{*}{ No } & \multirow{3}{*}{$\begin{array}{l}\text { Kepadatan } \\
\text { Penghuni }\end{array}$} & \multicolumn{4}{|c|}{ TB Paru } & \multicolumn{2}{|c|}{ Total } & \multirow{3}{*}{$\begin{array}{c}\text { P value } \\
(95 \% \text { CI) }\end{array}$} & \multirow{3}{*}{ OR } & \multirow{3}{*}{ CI (95\%) } \\
\hline & & \multicolumn{2}{|c|}{ Kasus } & \multicolumn{2}{|c|}{ Kontrol } & & & & & \\
\hline & & $f$ & $\%$ & f & $\%$ & f & $\%$ & & & \\
\hline 1 & Tidak & & & & & & & \multirow{5}{*}{0,001} & \multirow{5}{*}{5,200} & \multirow{5}{*}{$1,901-14,220$} \\
\hline \multirow[b]{3}{*}{2} & Memenuhi & 26 & 72,2 & 12 & 33,3 & 38 & 52,8 & & & \\
\hline & Syarat & & & & & & & & & \\
\hline & $\begin{array}{l}\text { Memenuhi } \\
\text { Syarat }\end{array}$ & 10 & 27,8 & 24 & 66,7 & 34 & 47,2 & & & \\
\hline Tot: & & 36 & 100 & 36 & 100 & 72 & 100 & & & \\
\hline
\end{tabular}

Sumber : Data primer (Diolah, 2018)

jangan minum susu sapi mentah, bagi penderita sebaiknya tidak meludah sembarangan dan sewaktu bersin harus menutup mulut menggunakan sapu tangan, pencegahan terhadap penyakit TB paru dapat dilakukan dengan tidak melakukan kontak udara dengan penderita, minum obat pencegah dengan dosis yang tepat dan hidup sehat, terutama rumah harus baik ventilasi udaranya dimana sinar matahari pagi masuk ke dalam rumah (Wijaya, 2012).

\subsection{Faktor Kualitas Lingkungan Dengan Penderita TB Paru BTA (+).}

Lingkungan sehat pada dasarnya adalah suatu kondisi atau keadaan lingkungan yang optimum sehingga berpengaruh terhadap terwujudnya status kesehatan yang optimum pula. Ruang lingkup kesehatan lingkungan antara lain: perumahan, pembuangan kotoran manusia, penyediaan air bersih, pembuangan sampah, pembuangan limbah, rumah hewan ternak dan sebagainya (Notoatmodjo, 2012).

Rumah sehat adalah bangunan rumah tinggal yang memenuhi syarat kesehatan, yaitu rumah yang memiliki jamban yang sehat, sarana air bersih, tempat pembuangan sampah, sarana pembuangan air limbah, ventilasi rumah yang baik, kepadatan hunian rumah yang sesuai dan lantai rumah yang tidak terbuat dari tanah. Rumah dan lingkungan yang tidak memenuhi syarat kesehatan beresiko menjadi sumber penyebab penularan berbagai jenis penyakit (Wulandari, 2012).

Kepadatan penghuni merupakan suatu proses penularan penyakit. Semakin padat maka perpindahan penyakit, khususnya penyakit menular melalui udara akan semakin mudah dan cepat, apalagi terdapat anggota keluarga yang menderita $\mathrm{Tb}$ paru dengan BTA (+). Kuman TB paru cukup resisten terhadap antiseptik tetapi dengan cepat akan menjadi inaktif oleh cahaya matahari, sinar ultraviolet yang dapat merusak atau melemahkan fungsi vital organisme dan kemudian mematikan. Kepadatan hunian ditempat tinggal penderita TB paru anak paling banyak ialah tingkat kepadatan rendah. Suhu di dalam ruangan erat kaitannya dengan kepadatan hunian dan ventilasi rumah (Behrman et al, 2012).

Kepadatan penghuni yang ditetapkan oleh Departemen Kesehatan RI, yaitu rasio luas lantai seluruh ruangan dibagi jumlah penghuni minimal $10 \mathrm{~m}^{2} /$ orang. Luas kamar tidur minimal $8 \mathrm{~m}^{2}$ dan tidak dianjurkan digunakan lebih 2 orang tidur dalam satu ruang tidur, kecuali anak dibawah umur 5 tahun. Kepadatan hunian dapat juga ditentukan dengan

Tabel 7. Hubungan lantai rumah dengan penderita TB paru BTA (+) di wilayah kerja Puskesmas Lhok Bengkuang Kabupaten Aceh Selatan tahun 2018

\begin{tabular}{|c|c|c|c|c|c|c|c|c|c|c|}
\hline \multirow{3}{*}{ No } & \multirow{3}{*}{ Lantai Rumah } & \multicolumn{4}{|c|}{ TB Paru } & \multicolumn{2}{|c|}{ Total } & \multirow{3}{*}{$\begin{array}{c}\text { P value } \\
\text { (95\% CI) }\end{array}$} & \multirow{3}{*}{ OR } & \multirow{3}{*}{ CI (95\%) } \\
\hline & & \multicolumn{2}{|c|}{ Kasus } & \multicolumn{2}{|c|}{ Kontrol } & & & & & \\
\hline & & f & $\%$ & f & $\%$ & f & $\%$ & & & \\
\hline 1 & Tidak & & & & & & & \multirow{4}{*}{0,015} & \multirow{4}{*}{1,977} & \multirow{4}{*}{$0,770-5,081$} \\
\hline & $\begin{array}{l}\text { Memenuhi } \\
\text { Syarat }\end{array}$ & 23 & 63,9 & 17 & 47,2 & 40 & 55,6 & & & \\
\hline 2 & $\begin{array}{l}\text { Memenuhi } \\
\text { Syarat }\end{array}$ & 13 & 36,1 & 19 & 52,8 & 32 & 44,4 & & & \\
\hline Tota & & 36 & 100 & 36 & 100 & 72 & 100 & & & \\
\hline
\end{tabular}

Sumber : Data primer (Diolah, 2018) 
Tabel 8. Hubungan pencahayaan dengan penderita TB paru BTA (+) di wilayah kerja Puskesmas Lhok Bengkuang Kabupaten Aceh Selatan tahun 2018

\begin{tabular}{|c|c|c|c|c|c|c|c|c|c|c|}
\hline \multirow{3}{*}{ No } & \multirow{3}{*}{ Pencahayaan } & \multicolumn{4}{|c|}{ TB Paru } & \multirow{2}{*}{\multicolumn{2}{|c|}{ Total }} & \multirow{3}{*}{$\begin{array}{c}\text { P value } \\
\text { (95\% CI) }\end{array}$} & \multirow{3}{*}{ OR } & \multirow{3}{*}{ CI $(95 \%)$} \\
\hline & & \multicolumn{2}{|c|}{ Kasus } & \multicolumn{2}{|c|}{ Kontrol } & & & & & \\
\hline & & $\mathbf{f}$ & $\%$ & $\mathbf{f}$ & $\%$ & $\mathbf{f}$ & $\%$ & & & \\
\hline 1 & Tidak & & & & & & & \multirow{4}{*}{0,034} & \multirow{4}{*}{2,200} & \multirow{4}{*}{$0,857-5,645$} \\
\hline & Memenuhi & 22 & 61,1 & 15 & 41,7 & 37 & 37 & & & \\
\hline 2 & $\begin{array}{l}\text { Syarat } \\
\text { Memenuhi } \\
\text { Syarat }\end{array}$ & 14 & 38,9 & 21 & 58,3 & 35 & 35 & & & \\
\hline Total & & 36 & 100 & 36 & 100 & 72 & 100 & & & \\
\hline
\end{tabular}

Sumber : Data primer (Diolah, 2018)

jumlah kamar tidur dibagi dengan jumlah penghuni (sleeping density), dinyatakan dengan nilai: baik, bila kepadatan lebih atau sama dengan 0,7 cukup, bila kepadatan antara 0,5 - 0,7 dan kurang bila kepadatan kurang dari 0,5 (Azhar, 2012).

Menurut indikator pengawasan rumah, luas ventilasi yang memenuhi syarat kesehatan adalah $\geq 10 \%$ luas lantai rumah dan luas ventilasi yang tidak memenuhi syarat kesehatan adalah $<10 \%$ luas lantai rumah. Luas ventilasi rumah yang $<10 \%$ dari luas lantai (tidak memenuhi syarat kesehatan) akan mengakibatkan berkurangnya konsentrasi oksien dan bertambahnya (Depkes RI, 2012).

Untuk memperoleh penerangan yang baik selain memanfaatkan penerangan matahari sebanyak mungkin untuk menerangi ruangan rumah pada siang hari melalui jendela, lubang ventilasi pintu atau atap rumah, gunakan pewarnaan yang muda atau cerah untuk lantai, dinding maupun langit-langit rumah dan gunakan listrik yang cukup yang tidak menyilaukan mata pada malam harinya (Chandara, 2012).

Lantai rumah yang sehat adalah lantai yang kedap air sebagai syarat utama bagi rumah yang sehat. Bahan yang digunakan bisa seperti kayu, semen, keramik, atau ubin. Lantai yang berdebu atau becek tidak membuat penghuni menjadi nyaman dan menjadi sarang penyakit. Pemilihan bahan material lantai sangat penting, seperti keramik lantai yang licin dapat menyebabkan penghuni dapat terpeleset (Kemenkes, 2012).

Jenis lantai tanah memiliki peran terhadap proses kejadian TB paru, melalui kelembaban dalam ruangan. Lantai tanah cenderung menimbulkan kelembaban pada musim panas lantai menjadi kering sehingga dapat menimbulkan debu yang berbahaya bagi penghuni rumah (Fatimah, 2013).

Rumah sehat memiliki sistem pencahayaan alami yang cukup. Bila terdapat rumah yang kurang sistem pencahayaan matahari, maka akan sangat lembab, tidak nyaman dan rawan terhadap bibit penyakit. Secara umum, cahaya alami didapat melewati jendela, tetapi tidak memungkinkan cahaya bisa diperoleh dari genteng yang terbuat dari kaca. Sebaiknya tidak terlalu berlebihan membuat sistem pencahaayan, karena akan membuat penghuni menjadi gerah akibat ruangan yang terlalu terang (Kemenkes, 2012).

Kuman tuberkulosis dapat bertahan hidup bertahun-tahun lamanya, dan mati bila terkena sinar matahari, sabun, lisol, karbol dan panas api. Rumah yang tidak masuk sinar matahari mempunyai resiko menderita tuberkulosis 3-7 kali dibandingkan dengan rumah yang dimasuki sinar matahari (Azhar, 2012). Pencahayaan alam dan buatan langsung maupun tidak langsung dapat menerangi seluruh ruangan minimal intensitasnya 60 lux dan tidak menyilaukan (Depkes RI, 2012).

\section{Metodologi Penelitian}

\subsection{Jenis Penelitian}

Jenis Penelitian ini merupakan penelitian survei yang bersifat analitik dengan desain penelitian case control yaitu penelitian survei analitik dimana subjek yaitu kasus dan kontrol telah diketahui dan dipilih berdasarkan telah mempunyai keluaran (out come) dari puskesmas. untuk melihat hubungan antara faktor lingkungan fisik rumah dengan penderita TB paru BTA $(+)$ di Wilayah Kerja Puskesmas Lhok Bengkuang Kecamatan Tapaktuan Kabupaten Aceh Selatan Tahun 2018.

\subsection{Populasi dan Sampel}

Populasi dalam penelitian ini adalah semua penderita TB paru BTA $(+)$ yang tercatat dalam laporan data kasus di wilayah kerja Puskesmas Lhok Bengkuang Kecamatan Tapaktuan Kabupaten Aceh Selatan Tahun 2017 yaitu sebanyak 36 penderita TB Paru (+).

Untuk menentukan ukuran dan besarnya sampel dalam penelitian ini digunakan total populasi yaitu responden yang menderita TB paru $(+)$ sebanyak 
36 kasus dan yang non TB Paru sebanyak 36 kasus. Dapat dilihat pada Tabel 1.

\subsection{Jenis Data}

Adapun jenis data yang digunakan dalam penelitian ini adalah data primer dan data sekunder.

1. Data primer yaitu data yang diambil dengan cara membagikan kuesioner kepada responden yaitu penderita TB Paru BTA (+). Kuesioner yang akan diberikan kepada responden harus terlebih dulu mendapat persetujuan dan ditandatangani oleh responden tersebut. Sebelum mengisi kuesioner, responden diberi penjelasan tentang cara pengisiannya. Jika responden mengalami kesulitan untuk memahami atau menjawab kuesioner maka peneliti akan memberikan penjelasan yang dapat dipahami oleh responden.

2. Data sekunder yaitu berupa data yang didapatkan dari Puskesmas Lhok Bengkuang.

Adapun pengumpulan data primer dalam penelitian ini dilakukan dengan wawancara terhadap responden untuk menggali informasi yang relevan dengan tujuan penelitian. Penyebaran kuesioner pengumpulan data dengan menggunakan daftar pertanyaan yang telah dibuat dalam memperoleh data dalam penelitian, dimana kuesioner tersebut diajukan hal-hal yang relevan dan berkaitan dengan tujuan penelitian. Selain itu juga dilakukan observasi atau pengamatan langsung terhadap objek penelitian guna memperoleh bahan dan data-data yang diperlukan.

\section{Hasil Dan Pembahasan}

\subsection{Analisis Univariat}

Analisis univariat menggunakan distribusi frekuensi terhadap variabel kepadatan penghuni, lantai rumah, pencahayaan dan ventilasi rumah disajikan pada Tabel 2.

Tabel 2. menunjukkan bahwa responden dengan kepadatan penghuni tidak memenuhi syarat di Wilayah Kerja Puskesmas Lhok Bengkuang Kecamatan Tapaktuan Kabupaten Aceh Selatan, sebanyak $72,2 \%$ mengalami TB Paru (+) dibandingkan dengan responden yang non TB Paru 33,3\%. Sedangkan responden dengan kepadatan penghuni memenuhi syarat di Wilayah Kerja Puskesmas Lhok Bengkuang Kecamatan Tapaktuan Kabupaten Aceh Selatan, sebanyak $66,7 \%$ yang non TB Paru dibandingkan dengan responden $27,8 \%$.

Sementara untuk kondisi kelayakan lantai rumah dapat dilihat pada Tabel 3. yang menunjukkan bahwa responden dengan lantai rumah tidak memenuhi syarat di Wilayah Kerja Puskesmas Lhok Bengkuang
Kecamatan Tapaktuan Kabupaten Aceh Selatan, sebanyak 63,9\% mengalami TB Paru (+) dibandingkan dengan responden yang non TB Paru 47,2\%.

Sedangkan responden dengan lantai rumah memenuhi syarat di Wilayah Kerja Puskesmas Lhok Bengkuang Kecamatan Tapaktuan Kabupaten Aceh Selatan, sebanyak 52,8\% yang non TB Paru dibandingkan dengan responden $36,1 \%$.

Tabel 4 menunjukkan bahwa responden dengan pencahayaan tidak memenuhi syarat di Wilayah Kerja Puskesmas Lhok Bengkuang Kecamatan Tapaktuan Kabupaten Aceh Selatan, sebanyak 61,1\% mengalami TB Paru (+) dibandingkan dengan responden yang non TB Paru 41,7\%.

Sedangkan responden dengan pencahayaan memenuhi syarat di Wilayah Kerja Puskesmas Lhok Bengkuang Kecamatan Tapaktuan Kabupaten Aceh Selatan, sebanyak 58,3\% yang non TB Paru dibandingkan dengan responden $38,9 \%$.

Tabel 5 menunjukkan bahwa responden dengan ventilasi rumah tidak memenuhi syarat di Wilayah Kerja Puskesmas Lhok Bengkuang Kecamatan Tapaktuan Kabupaten Aceh Selatan, sebanyak 55,6\% mengalami TB Paru (+) dibandingkan dengan responden yang non TB Paru $47,2 \%$.

Sedangkan responden dengan pencahayaan memenuhi syarat di Wilayah Kerja Puskesmas Lhok Bengkuang Kecamatan Tapaktuan Kabupaten Aceh Selatan, sebanyak 52,8\% yang non TB Paru dibandingkan dengan responden $44,4 \%$.

\subsection{Analisis Bivariat}

Analisis bivariat menggunakan Chi-Square untuk mengetahui hubungan antara kepadatan penghuni, lantai rumah, pencahayaan, ventilasi rumah dengan penderita TB paru BTA (+) di Wilayah Kerja Puskesmas Lhok Bengkuang Kecamatan Tapaktuan Kabupaten Aceh Selatan Tahun 2018.

Dari Tabel 6. diketahui dari 38 responden yang kepadatan penghuninya tidak memenuhi syarat lebih besar TB Paru (+) sebesar 72,2\% dibandingkan non TB sebesar 33,3\%. Sedangkan dari 34 responden yang kepadatan penghuninya memenuhi syarat lebih besar non TB sebesar 66,7\% dibandingkan TB Paru (+) sebesar 27,8\%. Hasil uji Chi-Square diperoleh nilai $\mathrm{P}$-value $=0,001$. Hal tersebut menunjukkan ada hubungan antara kepadatan penghuni dengan penderita TB paru BTA (+) di Wilayah Kerja Puskesmas Lhok Bengkuang Kecamatan Tapaktuan Kabupaten Aceh Selatan Tahun 2018, dan diperoleh nilai odd ratio (OR) sebesar 5,200 yang artinya responden dengan kepadatan penghuni tidak memenuhi syarat beresiko mengalami TB Paru (+) 5 kali lipat dibandingkan 
dengan kepadatan penghuni yang memenuhi syarat.

Dari Tabel 7. diketahui dari 40 responden yang lantai rumah tidak memenuhi syarat lebih besar TB Paru (+) sebesar 63,9\% dibandingkan non TB sebesar 47,2\%. Sedangkan dari 32 responden yang lantai rumah memenuhi syarat lebih besar non TB sebesar 52,8\% dibandingkan TB Paru (+) sebesar 36,1\%. Hasil uji Chi-Square diperoleh nilai P-value $=0,015$. Hal tersebut menunjukkan ada hubungan antara lantai rumah dengan penderita TB paru BTA $(+)$ di Wilayah Kerja Puskesmas Lhok Bengkuang Kecamatan Tapaktuan Kabupaten Aceh Selatan Tahun 2018, dan diperoleh nilai odd ratio (OR) sebesar 1,977 yang artinya responden dengan lantai rumah tidak memenuhi syarat beresiko mengalami TB Paru $(+)$ 1 kali lipat dibandingkan dengan lantai rumah yang memenuhi syarat.

Dari Tabel 8. diketahui dari 37 responden yang pencahayaan tidak memenuhi syarat lebih besar TB Paru (+) sebesar 61,1\% dibandingkan non TB sebesar 38,9\%. Sedangkan dari 35 responden yang pencahayaan memenuhi syarat lebih besar non TB sebesar 58,3\% dibandingkan TB Paru (+) sebesar 38,9\%. Hasil uji Chi-Square diperoleh nilai $\mathrm{P}$-value $=0,034$. Hal tersebut menunjukkan ada hubungan antara pencahayaan dengan penderita TB paru BTA $(+)$ di Wilayah Kerja Puskesmas Lhok Bengkuang Kecamatan Tapaktuan Kabupaten Aceh Selatan Tahun 2018, dan diperoleh nilai odd ratio (OR) sebesar 2,200 yang artinya responden dengan pencahayaan tidak memenuhi syarat beresiko mengalami TB Paru (+) 2 kali lipat dibandingkan dengan pencahayaan yang memenuhi syarat.

Dari Tabel 9. diketahui dari 37 responden yang ventilasi rumah tidak memenuhi syarat lebih besar TB Paru (+) sebesar 55,6\% dibandingkan non TB sebesar 47,2\%. Sedangkan dari 35 responden yang ventilasi rumah memenuhi syarat lebih besar non TB sebesar 52,8\% dibandingkan TB Paru $(+)$ sebesar 44,4\%. Hasil uji Chi-Square diperoleh nilai P-value $=0,047$. Hal tersebut menunjukkan ada hubungan antara ventilasi rumah dengan penderita TB paru BTA (+) di Wilayah Kerja Puskesmas Lhok Bengkuang Kecamatan Tapaktuan Kabupaten Aceh Selatan Tahun 2018, dan diperoleh nilai odd ratio (OR) sebesar 2,397 yang artinya responden dengan ventilasi rumah tidak memenuhi syarat beresiko mengalami TB Paru (+) 2 kali lipat dibandingkan dengan ventilasi rumah yang memenuhi syarat.

Berdasarkan hasil penelitian menunjukkan ada hubungan antara kepadatan penghuni dengan penderita TB paru BTA (+) di Wilayah Kerja Puskesmas Lhok Bengkuang Kecamatan Tapaktuan Kabupaten Aceh
Selatan Tahun 2018, dengan nilai p-value $=0,001$. dan diperoleh nilai odd ratio (OR) sebesar 5,200 yang artinya responden yang kepatan penghuni tidak memenuhi syarat seperti didalam satu rumah di huni lebih dari 1 kepala keluarga, kamar tidur dihuni 3 orang, dan untuk balita luas kamar tidur $<9 \mathrm{~m}^{3}$ lalu dihuni beberapa orang sehingga lingkungan fisik rumah responden dapat beresiko terkena TB Paru BTA (+) 2 kali lipat dibandingkan yang memenuhi syarat. Untuk mencegah terjadinya TB Paru BTA (+) responden harus didalam satu rumah di huni tidak lebih dari 1 kepala keluarga, kamar tidur dihuni 2 orang maksimal, dan untuk balita luas kamar tidur $>9$ $\mathrm{m}^{3}$ tidak digabung dengan orang dewasa.

Peneliti berasumsi bahwa kepadatan penghuni menjadi faktor yang kejadian TB Paru. Hal ini dikarenakan responden yang menderita TB Paru (+) luas ruangan $<10 \mathrm{~m}^{2}$, luas kamar tidur $>8 \mathrm{~m}^{2}$ namun dihuni hingga 3 orang. Sedangkan responden dengan non TB memiliki luas ruangan $>10 \mathrm{~m}^{2}$, luas kamar tidur $>8 \mathrm{~m}^{2}$ dan dihuni hanya 2 orang saja.

Hubungan antara lantai rumah dengan penderita TB paru BTA (+) di Wilayah Kerja Puskesmas Lhok Bengkuang Kecamatan Tapaktuan Kabupaten Aceh Selatan Tahun 2018, dengan nilai p-value $=0,015$. dan diperoleh nilai odd ratio (OR) sebesar 1,977 yang artinya responden yang mempunyai lantai rumah tidak memenuhi syarat seperti lantai tidak terbuat dari semen halus, lantai tidak mudah dibersihkan, lantai bergenang air jika di bersihkan dengan air sehingga lingkungan fisik rumah responden dapat beresiko terkena TB Paru BTA (+) 2 kali lipat dibandingkan yang memenuhi syarat. Untuk mencegah terjadinya TB Paru BTA $(+)$ responden harus membuat lantai yang terbuat dari semen halus atau keramik, lantai mudah dibersihkan, lantai tidak bergenang air jika di bersihkan dengan air.

Peneliti berasumsi bahwa lantai rumah menjadi faktor yang memmpengaruhi kejadian TB Paru. hal ini dikarenakan responden yang menderita TB Paru (+) memiliki lantai dari semen dan tidak rata, lantai tidak mudah dibersihkan karena jika dibersihkan dengan di pel lantai terkadang dikenang air sehingga lantai lembab. Sedangkan responden dengan TB Paru (-) memiliki lantai rata tetapi sebagian besar masih terbuat dari semen dan lantai mudah dibersihkan tidak digenangi air.

Berdasarkan hasil penelitian menunjukkan ada hubungan antara pencahayaan dengan penderita TB paru BTA $(+)$ di Wilayah Kerja Puskesmas Lhok Bengkuang Kecamatan Tapaktuan Kabupaten Aceh Selatan Tahun 2018, dengan nilai p-value $=0,034$. dan diperoleh nilai odd ratio (OR) sebesar 2,200 yang 
artinya responden yang mempunyai pencahayaan tidak memenuhi syarat seperti pintu rumah tidak pernah dibuka pagi hari yang menyebabkan matahri tidak bisa masuk, matahari yang masuk terhalang oleh ventilasi yang ditutup sehingga lingkungan fisik rumah responden dapat beresiko terkena TB Paru BTA (+) 2 kali lipat dibandingkan yang memenuhi syarat. Untuk mencegah terjadinya TB Paru BTA (+) responden harus mebuka pintu dipagi hari agar masuk udara segar dan cahaya matahri, cahaya matahri harus bisa masuk ke dalam rumah jangan dihalangi oleh jendela yang ditutup dengan kain atau semacamnya sehingga sinar matahri yang masuk dapat membunuh kuman yang ada di dalam rumah dan sehat bagi tubuh.

Pencahayaan menjadi faktor yang mempengaruhi kejadian TB Paru. Hal ini dikarenakan responden yang menderita TB Paru (+) tidak pernah membuka pintu di pagi hari agar masuk udara dan sinar matahari, begitu juga sinar matahari yang terhalang masuk kerumah karena jendela tidak dapat dibuka karena ditutupi seng atau semacamnya. .

Hubungan antara ventilasi rumah dengan penderita TB paru BTA $(+)$ di Wilayah Kerja Puskesmas Lhok Bengkuang Kecamatan Tapaktuan Kabupaten Aceh Selatan Tahun 2018, dengan nilai p-value $=0,038$. dan diperoleh nilai odd ratio (OR) sebesar 2,397 yang artinya responden yang mempunyai ventilasi rumah tidak memenuhi syarat seperti rumah tidak memiliki jendela yang bisa di buka tutup, lubang ventilasi $<5 \%$ dari luas lantai dan ventilasi di rumah responden tidak bisa masuk udara dengan bebas sehingga lingkungan fisik rumah responden dapat beresiko terkena TB Paru BTA (+) 2 kali lipat dibandingkan yang memenuhi syarat. Untuk mencegah terjadinya TB Paru BTA (+) responden harus memiliki ventilasi yang dapat dibuka dan ditutup, lubang ventilasi $>5 \%$ dari luas lantai sehingga udara yang ada didalam rumah sehat bagi responden.

Hasil penelitian sesuai dengan teori diatas, peneliti berasumsi bahwa ventilasi rumah mempengaruhi kejadian TB Paru, hal ini dikarenakan responden yang menderita TB Paru (+) tidak memiliki ventilasi permanen hanya di tutupi seng dan luasnya $<5 \%$, ventilasi tidak dapat masuk udara dengan bebas karena jendela tidak bisa dibuka dan ditutup. Sedangkan responden dengan non TB memiliki jendela yang bisa keluar masuk udara dengan bebas namun ukuran jendela masih saja $<5 \%$.

\section{Kesimpulan Dan Saran}

Berdasarkan penelitian yang dilakukan dapat disimpulkan bahwa:

1. Ada hubungan kepadatan penghuni dengan penderita TB paru BTA (+) di Wilayah Kerja Puskesmas Lhok Bengkuang Kecamatan Tapaktuan Kabupaten Aceh Selatan Tahun 2018, dengan nilai $\mathrm{OR}=5,200$.

2. Ada hubungan lantai rumah dengan penderita TB paru BTA (+) di Wilayah Kerja Puskesmas Lhok Bengkuang Kecamatan Tapaktuan Kabupaten Aceh Selatan Tahun 2018, dengan nilai OR =1,977.

3. Ada hubungan pencahayaan dengan penderita TB paru BTA $(+)$ di Wilayah Kerja Puskesmas Lhok Bengkuang Kecamatan Tapaktuan Kabupaten Aceh Selatan Tahun 2018, dengan nilai OR = 2,200 .

4. Ada hubungan ventilasi rumah dengan penderita TB paru BTA (+) di Wilayah Kerja Puskesmas Lhok Bengkuang Kecamatan Tapaktuan Kabupaten Aceh Selatan Tahun 2018, dengan nilai $\mathrm{OR}=2,397$.

Saran yang dapat diberikan sesuai dengan penelitian ini adalah:

1. Bagi Puskesmas perlu ditingkatkan upaya penjaringan terhadap penderita tuberkulosis paru baik secara aktif di lapangan maupun pasif di tempat pelayanan kesehatan dengan melibatkan langsung petugas kesehatan.

2. Bagi Masyarakat dalam membangun rumah untuk lebih memperhatikan aspek sanitasi rumah sehat seperti ventilasi, pencahayaan, kebiasaan membuka jendela dan lebih meningkatkan perilaku hidup bersih dan sehat untuk menghindari penularan penyakit tuberkulosis paru dengan memperhatikan asupan makanan yang bergizi.

3. Bagi peneliti selanjutnya yang berminat untuk melakukan penelitian lebih lanjut, peneliti merekomendasikan meneliti lebih dalam tentang faktor-faktor yang mempengaruhi penyakit TB Paru dengan variabel lain seperti umur, suhu ruangan, dan jenis dinding.

\section{Daftar Pustaka}

Aditama, T. (2012) Tuberkulosis, Masalah dan Penanggulangannya. Jakarta : UI Press.

Amir, M. (2012). Pengantar Ilmu Penyakit Paru, Surabaya : Airlangga University Press.

Atmosukarto. (2012). Tuberkulosis Paru, Diagnosis, Terapi dan Masalahnya, jld 4. Jakarta : UI Press

Azhar., (2012). Hubungan Lingkungan Fisik Rumah dengan Kejadian Penyakit Tuberkulosis Paru, Semarang: UNDIP.

Behrman et al, (2012). Ilmu Kesehatan Anak. Nelson Volume 3 Edisi 15 .Jakarta: EGC. 
Bustan, N. (2012). Epidemiologi Penyakit Tidak Menular, Jakarta: Rineka Cipta.

Chandara, (2012). Pengantar Kesehatan Lingkungan. Jakarta: EGC.

Crofton, (2012). Tuberculosis Klnik,Ed 2, Alih Bahasa : Harun M, dkk. Editor : Harun M. Jakarta, Widya Medika.

Daryatno. (2010). Tuberkulosis, Tatalaksana dan Masalahnya. Jakarta : UI Press.

Depkes RI, (2012). Pengawasan Penyehatan Lingkungan Pemukiman, Jakarta

Dinas Kesehatan Aceh, (2017). Laporan Pendenrita Tuberkulosis Tahun 2017. Aceh: DINKES Aceh.

Fatimah, (2013). Pemberantasan Penyakit TB Paru Dan Strategi Dots Bagian Paru. Medan: Fakultas Kedokteran Universitas Sumatera Utara.

Hiswani, (2014). Tuberkulosis Merupakan Penyakit Infeksi Yang Masih Menjadi Masalah Kesehatan Masyarakat, Medan: USU.

Indra, (2012). Pengobatan Standar TBC, l. Cermin dunia kedokteran, volume 137. Jakarta: Kalbe Farma.

Murti Bisma. (2011). Prinsip dan Metode Riset Epidemiologi. Yogyakarta : Gadjah Mada University Press.

Notoatmodjo, S, (2012). Pendidikan dan Perilaku Kesehatan, Jakarta: Rineka Cipta.

Nurhidayah, (2014). Hubungan Antara Karakteristik Lingkungan Rumah Dengan KejadianTuberkulosis (TB), Jakarta: FKUI.

Soemirat, J. (2012). Epidemiologi Lingkungan, Yogyakarta : Gajah Mada Uniersity Press.

Sudoyo, (2012). Buku Ajar Ilmu Penyakit Dalam, Jakarta: Interna Publishing.

Sugiarto, (2012). Metode Penelitian Kuntitatif Kualitatif dan $R$ \& D. Bandung : Alfabeta.

WHO, (2017). Pengobatan Tuberculosis Pedoman untuk Program-Program Nasional, Jakarta: Hipokrates.

Widoyono, (2011). Penyakit Tropis : Epidemiologi, Penularan, Pencegahan, dan. Pemberantasannya. Jakarta: Erlangga.

Wijaya, Merokok dan Tuberkulosis. Journal Tuberkulosis Indonesia, 8, 23-28. 2012. Yogyakarta:UNDIP. 2012

Wulandari. (2012). Hubungan Dukungan Sosial Dengan Kualitas Hidup Pada Penderita Tuberkulosis Paru (TB Paru) Di Balai Pengobatan Penyakit Paru (BP4) Yogyakarta Unit Pinggiran. Journal Tuberkulosis Indonesia, 8, 7-11. Yogyakarta:UNDIP.
Zulfikar. T, (2012). Tuberkulosis, Aceh: FK UNSYIAH dan RSUD ZA. 